\title{
ADMINISTRAÇÃO DE ESTOQUE E SUAS FERRAMENTAS DE GESTÃO: O ESTUDO DE CASO APLICADO AO PRODUTO ÓLEO MOTOR EM UMA EMPRESA DE AUTO PEÇAS
}

\author{
Paula Batista Cardoso (Faculdade Doctum) paulacardosojf@outlook.com \\ Sarita Hauck Menezes Pinto (Faculdade Doctum) saritahauck@ hotmail.com \\ Natália Fernandes Pinto (Faculdade Doctum) natyferf@hotmail.com
}

\section{Resumo}

As micro e pequenas empresas estão buscando estruturar seus processos gerenciais de forma a subsidia-las em suas tomadas de decisão e, consequentemente, reduzir seus custos. A gestão do estoque tem a função de deixar as empresas no nível em que o mercado exige e para auxiliar neste processo há ferramentas capazes de obter resultados que podem trazer mais eficácia na administração do estoque, dentre elas, a Curva ABC, o Estoque de Segurança e o Lote Econômico de Compras (LEC), ferramentas essas que foram estudas e aplicadas neste estudo. O estudo de caso foi aplicado em uma empresa do ramo de auto peças situada na cidade de Juiz de Fora - MG e tem como objetivo demonstrar a aplicabilidade dessas ferramentas de gestão no produto óleo motor. Ao aplicar a Curva ABC foi possível encontrar os produtos com o maior impacto financeiro, classificados como grupo A, e para este grupo foi calculado o Estoque de Segurança e o LEC. Ao aplicar essas duas ferramentas foi possível estabelecer o estoque de segurança e o ponto de pedido considerando a variação da demanda e o nível de serviço estipulado, além de determinar o lote econômico de compra ideal, estabelecendo a quantidade de itens que devem ser adquiridos com o menor custo possível.

Palavras-Chaves: Gestão de estoque; Curva ABC; Estoque de segurança; Lote Econômico de Compra

\section{Introdução}

Com o atual cenário econômico do país, onde a concorrência e a competitividade estão cada vez mais acirradas, as micro e pequenas empresas estão buscando estruturar seus processos gerenciais de forma a subsidia-las em suas tomadas de decisão.

Dentre as diversas áreas de uma organização, a gestão do estoque entra com a função de deixar as empresas no nível em que o mercado exige. De acordo com Bernardi (2012), 
administrar estoques significa manter os níveis de estoque o mais econômico possível, assim como práticos e objetivos, e que consigam trazer o melhor retorno de seus investimentos.

A má administração do estoque pode acarretar um giro inadequado de produtos, compras sem direcionamento, perda de vendas, e as consequências dessa má administração pode trazer muitos prejuízos para a organização (BERNARDI, 2012).

Para auxiliar o processo de administração do estoque há ferramentas capazes de obter resultados que podem trazer mais eficácia nas tomadas de decisão. Dentre elas, há a Curva $\mathrm{ABC}$, o Estoque de Segurança e o Lote Econômico de Compras (LEC), tais ferramentas foram estudas e aplicadas neste estudo.

O estudo de caso foi aplicado em uma empresa do ramo de auto peças situada na cidade de Juiz de Fora - MG. A empresa foi fundada em 2014, e tem como foco peças para veículos pesados, ou seja, para caminhões e carretas. Dentre os itens mais comercializados há os lubrificantes, filtros, peças de motor, parte elétrica e freio.

A finalidade deste estudo foi buscar uma forma de controle de estoque mais eficaz para o produto óleo motor, com o objetivo de reduzir os gastos e evitar a falta de produtos para atender os clientes.

\section{Revisão teórica}

\subsection{Gestão de estoque}

De acordo com Oliveira e Silva (2013), o estoque pode ser conceituado como tudo o que a empresa armazena para suprir as suas necessidades, ou seja, é tudo aquilo que precisa ser estocado em um determinado local, que garante a rotatividade dos produtos de modo rápido e eficaz.

O estoque tem a função de regular o fluxo do negócio, e a sua importância está em atender os clientes na hora certa, na quantidade certa, e este tem sido um dos maiores objetivos das empresas que trabalham com comércio em geral (MARTINS e ALT, 2002).

Na gestão de estoque deve-se levar em consideração a reposição dos itens, que tem como importância a definição de quando e quanto pedir de cada produto, e o que vai determinar é a previsão da demanda, feita com as informações de venda (GODOY, 2013). 
Para Amaral e Dourado (2011) um bom controle do estoque é essencial, pois este pode absorver cerca de $25 \%$ a $40 \%$ dos custos totais das empresas.

Um dos aspectos mais criticados em se manter um estoque é o fato de acarretar custos onerosos para a empresa. Contudo, apesar da manutenção de estoques gerar custos adicionais, a sua utilização acaba reduzindo, indiretamente, os custos operacionais com fornecedores, de modo a compensar os custos ligados ao estoque (BALLOU, 2006).

\subsection{Curva ABC}

A curva $\mathrm{ABC}$ permite identificar aqueles itens que necessitam de uma atenção maior e um tratamento mais adequado. Ela tem sido usada para a gestão de estoques, para definição de políticas de vendas e estabelecimento de prioridades (PIMENTEL, et al, 2017).

De acordo com Godoy (2013), a curva ABC é um sistema de classificação e se baseia em determinar três níveis de produtos (A, B e C), no entanto os níveis apresentados são estimados e podem variar. O nível A representa cerca de $80 \%$ do montante financeiro e engloba aproximadamente $20 \%$ dos itens; o nível B representa $15 \%$ do valor e $30 \%$ dos produtos, e o nível C corresponde aproximadamente $5 \%$ do financeiro total e $50 \%$ do total de produtos estocados.

Os autores Peinaldo e Graeml (2007) ressaltam que as porcentagens de classificação de cada nível da Curva ABC podem variar de empresa para empresa.

\subsection{Estoque mínimo de segurança}

Os estoques de segurança permitem que as empresas consigam manter um nível de estoque considerando a probabilidade de incertezas acontecerem (PEINADO e GRAEML, 2007).

Por considerar essas incertezas, os autores Pimentel et al (2017), citam que o estoque de segurança torna-se uma variável essencial para mensurar o ponto de pedido.

Ballou (2006) cita quando o estoque é reduzido ao ponto em que sua quantidade se mostra igual ou menor do que um nível do ponto de pedido é necessário o ressuprimento. 
Assim, Santos e Rodrigues (2006), citam que os estoques de segurança existem por causa das incertezas da demanda e do lead time (tempo entre o início e o fim de um processo) de fornecimento.

Para Martins e Alt (2002) essa ferramenta pode ser considerada em três situações: demanda variável e tempo de atendimento constante, demanda constante e tempo de atendimento variável, e demanda e tempo de atendimento variável.

A figura 1 representa graficamente essa situação, onde o Tempo de Atendimento (TA) ou de reposição é constante, e ao ser atingido o Ponto de Pedido (PP), um novo pedido de compra é emitido.

Figura 1 - Estoque de Segurança com Demanda (D) Variável e TA Constante

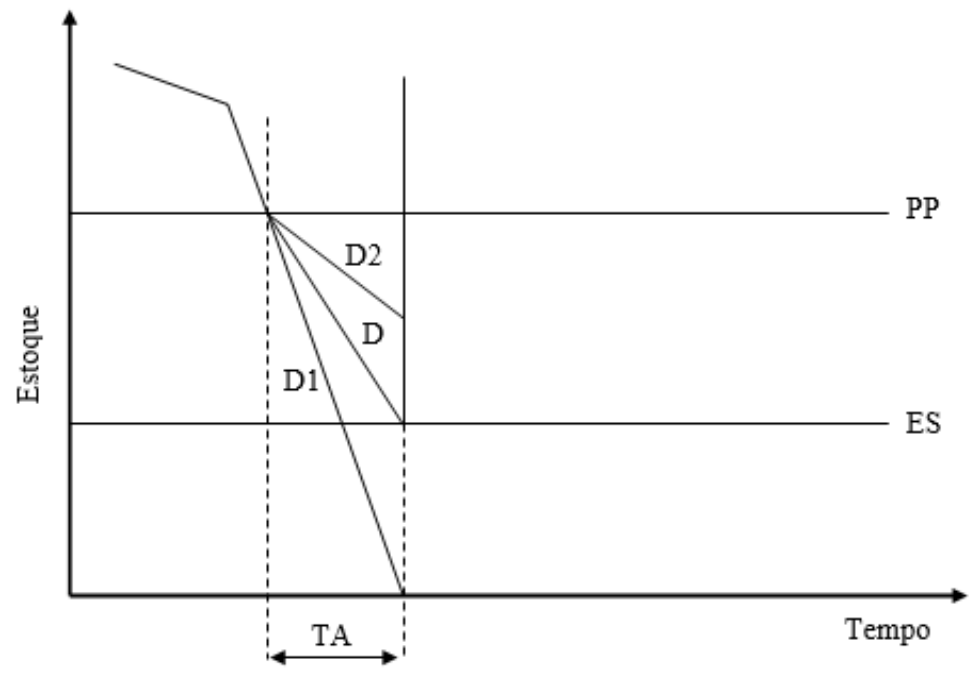

Fonte: Martins e Alt (2002), adaptado pela autora.

Nessa situação, o estoque de segurança pode ser calculado levando em consideração a variação da demanda durante o tempo de atendimento através da equação 1:

Equação 1 - Estoque de Segurança com tempo de reposição fixo

$$
\mathrm{ES}=\mathrm{Z} \mathrm{x} \sigma \mathrm{d} \mathrm{x} \sqrt{\mathrm{L}}
$$

Fonte: Martins e Laugeni (2005)

Em que:

ES: Estoque de Segurança

Z: Coeficiente da distribuição normal em função do nível de serviço desejado 
бd: Desvio padrão da demanda

L: Tempo de reposição ou Lead Time

Para Martins e Laugeni (2005) o cálculo do ponto de pedido consegue demonstrar o momento de quando iniciar a reposição do estoque antes que seja necessário utilizar o quantitativo do estoque de segurança. O Ponto de Pedido pode ser calculado através da equação 2.

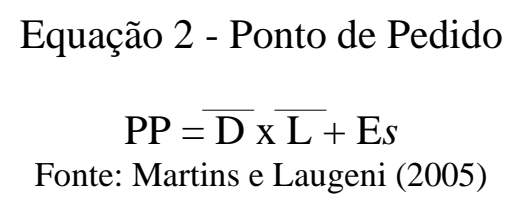

Em que:

PP: Ponto de Pedido

D: Demanda Média

L: Tempo de reposição ou Lead Time

Es: Estoque de Segurança

\subsection{Lote econômico de compra (LEC)}

O Lote Econômico de Compra (LEC) tem como objetivo buscar uma quantidade de estoque econômico e eficaz, através dos pedidos com fornecedores. Essa ferramenta ajuda na determinação de quando fazer o reabastecimento do estoque, criando um ponto de equilíbrio que possa reduzir os custos com estocagem (MARTINS e LAUGENI, 2005).

Peinado e Graeml (2017) ressaltam que, quanto maior o volume de estoque, maior será o custo com estocagem. No entanto deve-se levar em consideração que um maior volume de estoque implica em menores números de entrega, o que pode reduzir o custo com pedido. Por outro lado, quanto menor o volume de estoque o custo de estocagem reduz, mas o custo com pedido fica mais elevado.

O custo com pedidos compreende os gastos envolvidos no levantamento da necessidade do pedido, a forma de negociação, até o seu efetivo atendimento, pode ser calculado através da equação 3. 
Equação 3 - Equação do Custo do Pedido

$$
\mathrm{CP}=\mathrm{C} p \times \frac{\mathrm{D}}{\mathrm{LC}}
$$

Fonte: Peinado e Graeml (2017)

Em que:

CP: Custo Total com Pedidos

$\mathrm{C} p$ : Custo Unitário de um pedido

D: Demanda no período

LC: Lote de Compra

Já o custo de estocagem é definido por Peinado e Graeml (2017) como o custo financeiro de se manter o produto armazenado no estoque durante um determinado período de tempo, e pode ser representado pela equação 4 .

\section{Equação 4 - Equação do Custo de Estocagem}

$$
\mathrm{CE}=t \times \mathrm{C} u \times \frac{\mathrm{LC}}{2}
$$

Fonte: Peinado e Graeml (2017)

Em que:

CE: Custo Financeiro de Estocagem

$t$ : Taxa de juros ou custo de oportunidade

$\mathrm{Cu}$ : Custo unitário do material

\section{LC: Lote de Compra}

De acordo com Martins e Laugeni (2005) para determinar o LEC, define-se que o custo com este sistema seja igual ao somatório dos custos do material comprado, com o custo da gestão das compras e o custo financeiro de manter o estoque. Sendo LEC o lote econômico de compras, pode-se utilizar a equação 5: 
Equação 5 - Equação do Lote Econômico de Compras

$$
L E C=\sqrt{\frac{2 \times D \times C p}{t \times C u}}
$$

Fonte: Peinado e Graeml (2017)

Em que:

D: Demanda no período

Cp: Custo Unitário do Pedido

$t$ : Taxa de juros ou custo de oportunidade

$\mathrm{Cu}$ : Custo unitário do material

Segundo Martins e Laugeni (2005), para que os custos do LEC cheguem a um ponto mínimo, os custos de efetuar a compra e os custos financeiros devem ser iguais, conforme demonstrado na figura 2.

Figura 2 - Ponto de custo mínimo do LEC

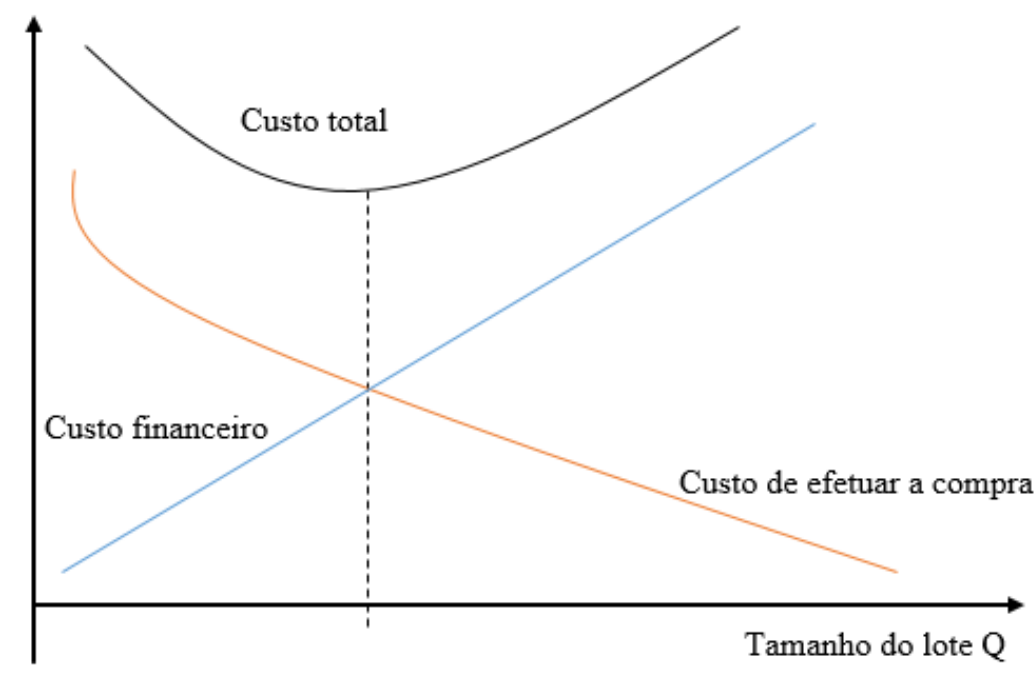

Fonte: Martins e Laugeni (2005), adaptado pela autora.

De acordo com Pimentel, et al (2017) para o cálculo do lote econômico de compra é necessário determinar o ponto de pedido para definir o momento certo de repor o estoque. 


\section{Metodologia}

Para aplicar as ferramentas de gestão foi necessário fazer o levantamento das informações através dos relatórios de compra e vendas dos produtos óleos motores. Diante disto, foi criado um banco de dados no software Microsoft Excel 2013, detalhando os itens para vendas, a quantidade de entradas, o preço de compra, o preço de venda, o fornecedor, a especificação da embalagem, a quantidade vendida e a data da compra e da entrega.

Primeiramente, foi analisado o histórico de vendas no período de 1 (um) ano, de janeiro a dezembro de 2018, e consistiu na verificação do consumo do produto óleo motor, em valor monetário e quantitativo. Aplicou-se a curva $\mathrm{ABC}$ para identificar quais os óleos lubrificantes apresentam que apresentam maiores custos no estoque, definindo assim quais os itens que devem receber maior atenção.

Para encontrar o estoque de segurança dos produtos classificados como "A", foi necessário estabelecer o coeficiente da distribuição normal em função do nível de serviço desejado. A empresa estimou que o estoque tenha um nível de serviço que atenda 95\% durante o ciclo. Diante disto, de acordo com o Quadro 1, o valor de " $Z$ ” foi estabelecido como 1,64.

Quadro 1 - Nível de serviço (TR) e Número de desvios padrões (Z)

\begin{tabular}{|c|c|c|c|c|c|c|c|c|}
\hline $\begin{array}{l}\text { Nivel de } \\
\text { serviço } \\
\text { durante } \\
\text { TR }\end{array}$ & $\begin{array}{c}\text { Número } \\
\text { desvios } \\
\text { padrões } \\
\text { Z }\end{array}$ & $\begin{array}{l}\text { Número de } \\
\text { falta } \\
\text { esperado } \\
\operatorname{NFE}(Z)\end{array}$ & $\begin{array}{l}\text { Nível de } \\
\text { serviço } \\
\text { durante } \\
\text { TR }\end{array}$ & $\begin{array}{c}\text { Número } \\
\text { desvios } \\
\text { padrões } \\
\text { Z }\end{array}$ & $\begin{array}{c}\text { Número de } \\
\text { falta } \\
\text { esperado } \\
\operatorname{NFE}(Z)\end{array}$ & $\begin{array}{l}\text { Nivel de } \\
\text { serviço } \\
\text { durante } \\
\text { TR }\end{array}$ & $\begin{array}{c}\text { Número } \\
\text { desvios } \\
\text { padrões } \\
\text { Z }\end{array}$ & $\begin{array}{l}\text { Número } \\
\text { de falta } \\
\text { esperado } \\
\operatorname{NFE}(Z)\end{array}$ \\
\hline 0,5000 & 0,00 & 0,399 & 0,8770 & 1,16 & 0,061 & 0,9898 & 2,32 & 0,003 \\
\hline 0,5160 & 0,04 & 0,379 & 0,8849 & 1,20 & 0,056 & 0,9909 & 2,36 & 0,003 \\
\hline 0,5319 & 0,08 & 0,360 & 0,8925 & 1,24 & 0,052 & 0,9918 & 2,40 & 0,003 \\
\hline 0,5478 & 0,12 & 0,342 & 0,8997 & 1,28 & 0,048 & 0,9927 & 2,44 & 0,002 \\
\hline 0,5636 & 0,16 & 0,324 & 0,9066 & 1,32 & 0,044 & 0,9934 & 2,48 & 0,002 \\
\hline 0,5793 & 0,20 & 0,307 & 0,9131 & 1,36 & 0,040 & 0,9941 & 2,52 & 0,002 \\
\hline 0,5948 & 0,24 & 0,290 & 0,9192 & 1,40 & 0,037 & 0,9948 & 2,56 & 0,002 \\
\hline 0,6103 & 0,28 & 0,275 & 0,9251 & 1,44 & 0,034 & 0,9953 & 2,60 & 0,001 \\
\hline 0,6255 & 0,32 & 0,256 & 0,9306 & 1,48 & 0,031 & 0,9959 & 2,64 & 0,001 \\
\hline 0,6406 & 0,36 & 0,237 & 0,9357 & 1,52 & 0,028 & 0,9963 & 2,68 & 0,001 \\
\hline 0,6554 & 0,40 & 0,230 & 0,9406 & 1,56 & 0,026 & 0,9967 & 2,72 & 0,001 \\
\hline 0,6700 & 0,44 & 0,217 & 0,9452 & 1,60 & 0,023 & 0,9971 & 2,76 & 0,001 \\
\hline 0,6844 & 0,48 & 0,204 & 0,9495 & 1,64 & 0,021 & 0,9974 & 2,80 & 0,0008 \\
\hline 0,6985 & 0,52 & 0,192 & 0,9535 & 1,68 & 0,019 & 0,9977 & 2,84 & 0,0007 \\
\hline 0,7123 & 0,56 & 0,180 & 0,9573 & 1,72 & 0,017 & 0,9980 & 2,88 & 0,0006 \\
\hline 0,7257 & 0,60 & 0,169 & 0,9608 & 1,76 & 0,016 & 0,9982 & 2,92 & 0,0005 \\
\hline 0,7389 & 0,64 & 0,158 & 0,9641 & 1,80 & 0,014 & 0,9985 & 2,96 & 0,0004 \\
\hline 0,7517 & 0,68 & 0,148 & 0,9671 & 1,84 & 0,013 & 0,9987 & 3,00 & 0,0004 \\
\hline 0.7642 & 0,72 & 0,138 & 0,9699 & 1.88 & 0.012 & 0,9988 & 3,04 & 0,0003 \\
\hline
\end{tabular}

Fonte: Peinaldo e Graeml (2007). 
Para o cálculo do LEC primeiro foi necessário mensurar o custo com o pedido e foi feito um levantamento de todos os colaboradores envolvidos no processo de compra, assim como todas as atividades e o tempo de execução, com isso foi possível chegar a um custo administrativo de $\mathrm{R} \$ 26,26$. Outro fator que onerou o custo de pedido foram as taxas diversas, como o custo da emissão do boleto, que neste caso foi de $\mathrm{R} \$ 11,36$. Somando-se estes dois custos (administrativo e taxas diversas), obteve-se um custo total com pedido de $\mathrm{R} \$ 37,62$.

Logo foi necessário estabelecer a taxa de custo do estoque para o cálculo do custo de manter, para tal foi utilizado o custo de oportunidade, que foi estimado em 2,4\% a.m., com um custo efetivo total de $32,92 \%$ a.a.

\section{Análise dos resultados}

\subsection{Curva ABC}

O objetivo da análise dessa ferramenta foi encontrar o grupo de produtos classificados como "A" na Curva ABC, para serem avaliados de forma mais detalhada neste estudo. Após os cálculos foi possível classificar estes itens conforme verificado no Quadro 2.

Quadro 2 - Produtos Classificados como "A” na Curva ABC

\begin{tabular}{|l|l|c|l|c|c|c|}
\hline \multicolumn{1}{|c|}{ Item } & $\begin{array}{c}\text { Custo } \\
\text { Unitário } \\
\text { Médio }\end{array}$ & $\begin{array}{c}\text { Vend } \\
\text { as }\end{array}$ & Custo Total & $\begin{array}{c}\text { \% } \\
\text { Individ } \\
\text { ual }\end{array}$ & $\begin{array}{c}\text { \% } \\
\text { Acumul } \\
\text { ada }\end{array}$ & $\begin{array}{c}\text { Class } \\
\text { ificaç } \\
\text { ão }\end{array}$ \\
\hline $\begin{array}{l}\text { Lubrax/Shell Top Turbo } \\
\text { 15W40 20L }\end{array}$ & $\mathrm{R} \$ 184,72$ & 110 & $\mathrm{R} \$ 20.319,20$ & $43,32 \%$ & $43,32 \%$ & $\mathrm{~A}$ \\
\hline Óleo ATF Hidráulico 1L & $\mathrm{R} \$ 8,90$ & 414 & $\mathrm{R} \$ 3.684,60$ & $7,86 \%$ & $51,17 \%$ & $\mathrm{~A}$ \\
\hline Lubrax GL5 140 20L & $\mathrm{R} \$ 194,03$ & 15 & $\mathrm{R} \$ 2.910,45$ & $6,20 \%$ & $57,38 \%$ & $\mathrm{~A}$ \\
\hline Lubrax TRM4 80W 20L & $\mathrm{R} \$ 193,52$ & 12 & $\mathrm{R} \$ 2.322,24$ & $4,95 \%$ & $62,33 \%$ & $\mathrm{~A}$ \\
\hline Lubrax GL5 90 20L & $\mathrm{R} \$ 196,79$ & 8 & $\mathrm{R} \$ 1.574,32$ & $3,36 \%$ & $65,69 \%$ & $\mathrm{~A}$ \\
\hline Lubrax GL5 90 1L & $\mathrm{R} \$ 10,00$ & 144 & $\mathrm{R} \$ 1.440,00$ & $3,07 \%$ & $68,76 \%$ & $\mathrm{~A}$ \\
\hline Lubrax TRM5 140 1L & $\mathrm{R} \$ 11,69$ & 123 & $\mathrm{R} \$ 1.437,87$ & $3,07 \%$ & $71,82 \%$ & $\mathrm{~A}$ \\
\hline Lubrax Top Turbo 15W40 1L & $\mathrm{R} \$ 11,27$ & 121 & $\mathrm{R} \$ 1.363,67$ & $2,91 \%$ & $74,73 \%$ & $\mathrm{~A}$ \\
\hline Lubrax GL5 85W140 20L & $\mathrm{R} \$ 209,73$ & 6 & $\mathrm{R} \$ 1.258,38$ & $2,68 \%$ & $77,41 \%$ & $\mathrm{~A}$ \\
\hline Lubrax Tecno 15W40 1L & $\mathrm{R} \$ 12,73$ & 91 & $\mathrm{R} \$ 1.158,43$ & $2,47 \%$ & $79,88 \%$ & $\mathrm{~A}$ \\
\hline
\end{tabular}

Fonte: Elaborado pela autora (2019).

Conforme o Quadro 2, apenas 10 produtos se classificaram como "A" na curva $\mathrm{ABC}$, e estes produtos representam $79,88 \%$ da proporção monetária investida nessa linha de produto. A 
classificação dos demais óleos motores comercializados podem ser verificados no gráfico da Curva $\mathrm{ABC}$, na Figura 3.

\section{Figura 3 - Gráfico do Cálculo da Curva ABC}

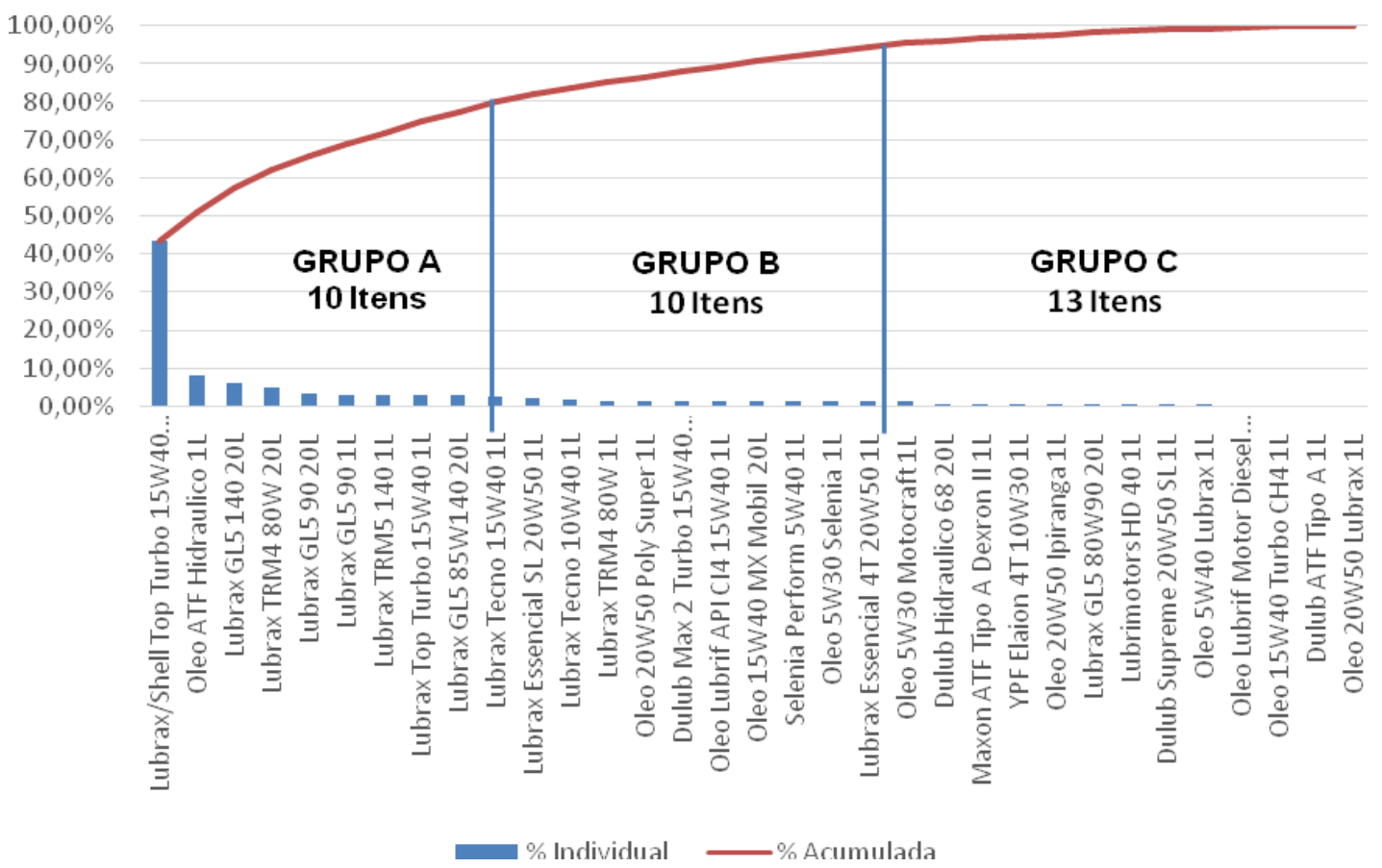

Fonte: Elaborado pela autora (2019).

Ressalta-se que os produtos que foram classificados no grupo "A" serão os itens de referência para aplicar as demais ferramentas apresentadas neste estudo.

\subsection{Estoque de Segurança}

Após estabelecer os produtos que possuem o maior valor agregado foi possível calcular o Estoque de Segurança. Com a aplicação dessa ferramenta, em conjunto com a definição do ponto de pedido, foi possível identificar o momento de iniciar o processo de compra antes de zerar o estoque, solucionando um problema recorrente no controle atualmente praticado na Auto Peças.

A tabela 1 demonstra qual a demanda anual de cada produto que foi classificado no grupo "A" da Curva ABC, e o lead time praticado pelo fornecedor, que configura-se o tempo compreendido entre a data do pedido e a entrega do produto, além do Estoque de Segurança ideal o Ponto de Pedido calculados. 
Tabela 1 - Resumo dos Resultados Obtidos do Estoque de Segurança

\begin{tabular}{llcccc}
\hline \multicolumn{1}{c}{ Itens } & $\begin{array}{c}\text { Demanda } \\
\text { Anual } \\
\text { (unid) }\end{array}$ & $\begin{array}{c}\text { Lead } \\
\text { Time } \\
\text { (Dias) }\end{array}$ & $\begin{array}{c}\text { Estoque de } \\
\text { Segurança } \\
\text { (unid) }\end{array}$ & $\begin{array}{c}\text { Ponto de } \\
\text { Pedido } \\
\text { (unid) }\end{array}$ \\
\hline 1 & Lubrax/Shell Top Turbo 15W40 20L & 110 & 3 & 3 & 4 \\
2 & Óleo ATF Hidráulico 1L & 414 & 3 & 5 & 9 \\
3 & Lubrax GL5 140 20L & 15 & 2 & 2 & 3 \\
4 & Lubrax TRM4 80W 20L & 12 & 3 & 1 & 2 \\
5 & Lubrax GL5 90 20L & 8 & 2 & 1 & 2 \\
6 & Lubrax GL5 90 1L & 144 & 2 & 4 & 5 \\
7 & Lubrax TRM5 140 1L & 123 & 2 & 3 & 4 \\
8 & Lubrax Top Turbo 15W40 1L & 121 & 3 & 4 & 5 \\
9 & Lubrax GL5 85W140 20L & 6 & 2 & 1 & 2 \\
10 & Lubrax Tecno 15W40 1L & 91 & 2 & 2 & 3 \\
\hline
\end{tabular}

Fonte: Elaborado pela autora (2019).

Considerando como exemplo o item 1 "Lubrax/Shell Top Turbo 15W40 20L", ao analisar os resultados obtidos, conclui-se que, quando o quantitativo deste produto no estoque chegar a 4 unidades é necessário emitir um novo pedido de compra.

Caso o fornecedor não tenha nenhum problema na entrega, estima-se que o novo pedido seja recebido antes de utilizar as 3 unidades do estoque de segurança. No entanto, se o fornecedor tiver algum problema e não conseguir fazer a entrega na data estipulada, a loja terá o estoque de segurança para atender a demanda até a entrega do item.

\subsection{Lote econômico de compra}

O LEC permite estabelecer a quantidade de itens que devem ser adquiridos com o mínimo custo possível, criando um ponto de equilíbrio entre a quantidade de estoque dos produtos e o reabastecimento.

Após os cálculos foi possível montar a Tabela 2 com os resultados obtidos dos 10 produtos analisados, considerando os custos do pedido de compra e os custos de manter o estoque conforme apesentado na metodologia. 
Tabela 2 - Resumo dos Resultados Obtidos do LEC

\begin{tabular}{llcccc}
\hline \multicolumn{1}{c}{ Itens } & Quant & $\begin{array}{c}\text { Custo Total } \\
(\mathbf{C M}+\mathbf{C P})\end{array}$ & $\begin{array}{c}\text { Pedidos por } \\
\text { Período } \\
\text { (Ano) }\end{array}$ & $\begin{array}{c}\text { Intervalos } \\
\text { entre Pedido } \\
\text { (Dias) }\end{array}$ \\
\hline $\begin{array}{l}\text { Lubrax/Shell Top Turbo 15W40 } \\
1\end{array}$ & 20L & 12 & 709,43 & 9 & 39 \\
2 & Óleo ATF Hidráulico 1L & 71 & 440,24 & 6 & 62 \\
3 & Lubrax GL5 140 20L & 4 & 268,49 & 4 & 102 \\
4 & Lubrax TRM4 80W 20L & 4 & 239,83 & 3 & 115 \\
5 & Lubrax GL5 90 20L & 3 & 197,47 & 3 & 139 \\
6 & Lubrax GL5 90 1L & 57 & 188,86 & 3 & 145 \\
7 & Lubrax TRM5 140 1L & 49 & 188,72 & 3 & 145 \\
8 & Lubrax Top Turbo 15W40 1L & 50 & 183,78 & 2 & 149 \\
9 & Lubrax GL5 85W140 20L & 3 & 176,55 & 2 & 156 \\
10 & Lubrax Tecno 15W40 1L & 40 & 169,39 & 2 & 162 \\
\hline
\end{tabular}

Fonte: Elaborado pela autora (2019)

Utilizando como exemplo o item 1 do grupo "A", segue a Figura 4 que demonstra graficamente a variação do custo por pedido, do custo de manter o estoque e do custo total, em função da quantidade encomendada do produto.

Figura 4 - LEC do produto "Lubrax /Shell Top Turbo 15W40 20L"

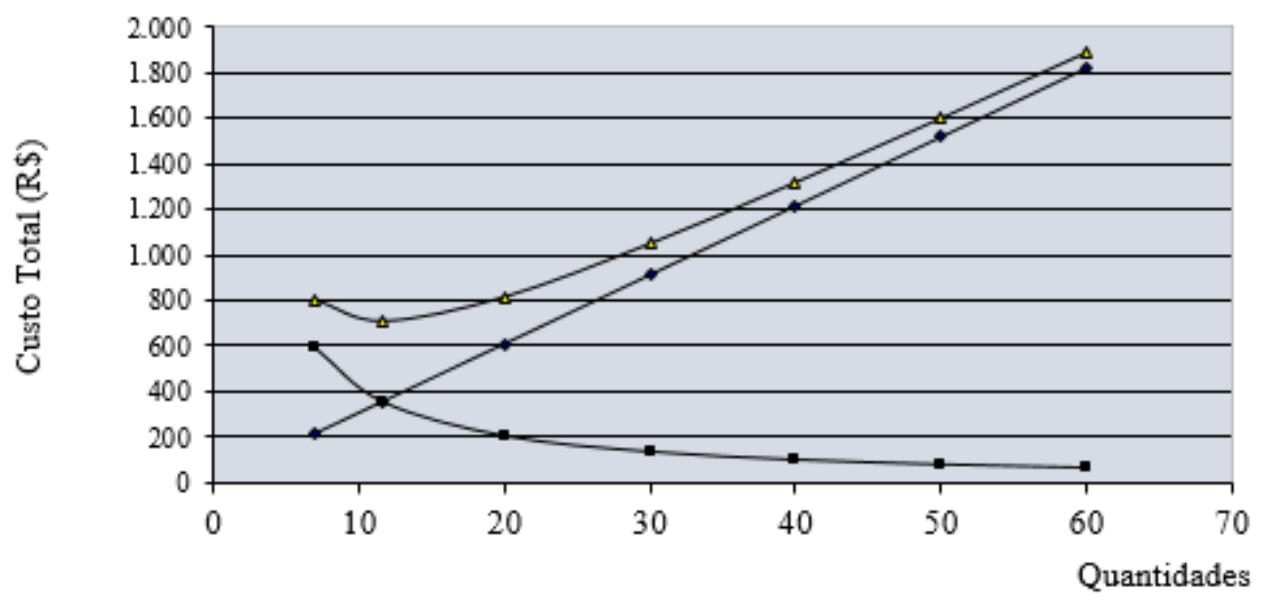


Observa-se que, ao atingir a quantidade encomendada de 12 itens, a linha referente ao custo de manter e a linha do custo por pedido se encontram, igualando os seus valores, perfazendo o valor de $\mathrm{R} \$ 354,71$, resultando em um custo total de $\mathrm{R} \$ 709,43$.

Fazendo a comparação do lote de compra praticado no período estudado do produto "Lubrax/Shell Top Turbo 15W40 20L", a loja fez 15 pedidos do produto, e em cada pedido foi adquirido uma média de 7 unidades. A Tabela 3 traz a informação dos custos do lote de compra praticado no período estudado e o lote de compra ideal calculado pelo LEC.

Tabela 3 - Análise do LEC do produto "Lubrax/Shell Top Turbo 15W40 20L"

\begin{tabular}{lccccc}
\hline Lote de Compra & $\begin{array}{c}\text { Quant. } \\
\text { Encomenda }\end{array}$ & $\begin{array}{c}\mathbf{N}^{\circ} \\
\text { Pedidos } \\
\text { por Ano }\end{array}$ & $\begin{array}{c}\text { Custo de } \\
\text { Manter }\end{array}$ & $\begin{array}{c}\text { Custo por } \\
\text { Pedido }\end{array}$ & $\begin{array}{c}\text { Custo } \\
\text { Total } \\
\text { (CM+CP) }\end{array}$ \\
\hline Atual & 7 & 15 & $\mathrm{R} \$ 212,83$ & $\mathrm{R} \$ 591,17$ & $\mathbf{R} \mathbf{8 0 4 , 0 1}$ \\
Calculado (LEC) & 12 & 9 & $\mathrm{R} \$ 354,71$ & $\mathrm{R} \$ 354,71$ & $\mathbf{R} \$ \mathbf{7 0 9 , 4 3}$ \\
\hline
\end{tabular}

Fonte: Elaborado pela autora (2019)

Nota-se que, quando a loja faz uma encomenda de 7 unidades por pedido o custo de manter é de $\mathrm{R} \$ 212,83$, e o custo por pedido é $\mathrm{R} \$ 591,17$, perfazendo um custo total de $\mathrm{R} \$ 804,01$.

Ao utilizar a quantidade por encomenda de 12 unidades, que foi o resultado encontrado pelo LEC, o número de pedidos no ano reduziria de 15 para 9, e o custo de manter e o custo por pedido passariam a ser iguais, com o valor de $\mathrm{R} \$ 354,71$, resultando em um custo total de $\mathrm{R} \$$ 709,43 .

Fazendo uma comparação entre o atual lote de compra e o ideal proposto pelo LEC, a diferença resultou em uma redução dos custos anuais de $\mathrm{R} \$ 94,58$, o equivalente a uma economia de $11,76 \%$ a.a.

\section{Considerações finais}

Após o estudo de caso pode-se observar a importância do gerenciamento do estoque na Auto Peças, obtendo maiores conhecimentos das atividades desenvolvidas, de forma a possibilitar um melhor planejamento e controle do estoque.

A escolha do grupo de lubrificantes como objeto do estudo foi muito importante, pois, além de ser um dos itens da loja com a menor margem de lucro, ele possui um alto custo de aquisição, e a falta deste item no estoque impacta negativamente na venda de outros produtos como Filtros e Aditivos. 
Em relação as ferramentas de gestão, foi possível estabelecer parâmetros que permitiu atingir a finalidade do estudo, que foi de trazer melhorias na organização e no processo de administração de estoque dos óleos motores.

A aplicação da curva $\mathrm{ABC}$ trouxe algumas surpresas, pois na concepção do comprador, os produtos com o maior custo unitário deveriam receber maior atenção, ou seja, os produtos com embalagem de 20 Litros. No entanto, ao considerar a demanda e o custo unitário, observou-se que, dentre os 10 produtos classificados como " $\mathrm{A}$ " na curva $\mathrm{ABC}, 5$ itens são referentes a embalagem de 1 Litro.

Um dos grandes problemas enfrentados na Auto Peças é o fato de esperar zerar o estoque para iniciar um novo processo de compra. Com a ferramenta de gestão Estoque de Segurança em conjunto com o Ponto de Pedido, foi possível determinar quando iniciar o processo de compras de cada item de forma a não zerar o estoque, mesmo que ocorra algum imprevisto na entrega.

Outro fator importante analisado no estudo foi estabelecer a quantidade de produtos que deve ser adquirido de forma a reduzir os custos envolvidos no processo. O LEC foi uma ferramenta muito importante neste processo, já que na Auto Peças nunca havia sido calculado os custos referentes ao pedido de compra e de manter o estoque.

Ao calcular o custo do pedido de compra foi possível fazer o levantamento das atividades inerentes a aquisição dos produtos, e ficou claro como esse processo é oneroso e demanda tempo. Diante disto percebeu-se que definir a quantidade de compra em relação aos custos do processo é muito importante para não onerar mais o produto.

Contudo, conclui-se que, a utilização dessas ferramentas pode auxiliar na tomada de decisão de compra na Loja de Auto Peças, de forma a otimizar o controle do estoque e, consequentemente, reduzir os custos do processo.

Sugere-se que as ferramentas sejam aplicadas nos demais produtos comercializados na Auto Peças de forma a estabelecer uma gestão de estoque eficaz e mais assertiva, assim a empresa não ficará refém apenas da experiência do comprador.

\section{Referências bibliográficas}

AMARAL, J. T.; DOURADO, L. O.. Gestão de Estoque. III Encontro Científico e Simpósio de Educação Unisalesiano. Out/2011. Disponível em: < http://www.unisalesiano.edu.br/simp osio2011/publicado/artigo0055.pdf>. Acessado em: 29 nov 2017. 
BALLOU, R. H. Gerenciamento da cadeia de suprimentos/logística empresarial. 5 ed. Porto Alegre: Bookman, 2006.

BERNARDI, L. A. Manual de empreendedorismo e gestão: fundamentos, estratégias e dinâmicas. 2 ed. São Paulo: Atlas, 2012.

GODOY, K. D.. Gestão de Estoque para Pequenas Empresas. 29fls. Monografia (Curso de Administração) - Centro Universitário de Brasília Faculdade de Ciências Sociais Aplicadas FATECS, Brasília, 2013.

MARTINS, P. G; ALT, P. R. Administração de materiais e recursos patrimoniais. São Paulo: Saraiva, 2002.

MARTINS, P. G.; LAUGENI, F. P.. Administração da produção. 2 ed. rev. São Paulo: Saraiva, 2005.

OLIVEIRA, M. M. E. P.; SILVA, R. M. R.. Gestão de Estoque. Cuiabá, 2013. Disponível em: < http://www.ice.edu.br/TNX/index.php?sid=49/>. Acessado em: 29 nov 2017.

PEINADO, J.; GRAEML, A. R.. Administração da produção: operações industriais e de serviços. Curitiba: UnicenP, 2007.

PIMENTEL, B. A. R.; COSTA NETO, S. R.; COSTA JUNIOR, E. H. G.. Estudo de caso: aplicação de um modelo de gestão de estoque em uma empresa na região metropolitana de Belém-PA. XXXVII Encontro Nacional de Engenharia de Produção. ENGEPE / ABEPRO, 2017. Joinville, SC.

SANTOS, A. M.; RODRIGUES, I. A.. Controle de estoque de materiais com diferentes padrões de demanda: estudo de caso em uma indústria química. Rev. Gestão \& Produção. v. 13, n2, p. 223-231, mai-ago. 2006. 